\title{
Home Language Shift and Its Implications for Language Planning in Singapore: From the Perspective of Prestige Planning
}

\author{
Shouhui Zhao and Yongbing Liu \\ Nanyang Technological University, Singapore
}

\begin{abstract}
Early research perceived language planning (LP) as a one-way process, underpinned by the positivistic view that the major problems facing language maintenance and spread could be solved through the application of the scientific method and careful planning by language planners (Baldauf, 2004). This perception continued until the 1990s, when some researchers (e.g., Haarmann, 1990) started a series of studies examining receptive processes in achieving LP goals, with the focus on a more fundamental but hidden agenda - human behavior and the psychological aspect in receiving the planned language product, which gives rise to a theory of prestige and image (Ager, 2005a \& 2005b) planning in the LP research literature.
\end{abstract}

In this paper, drawing upon the empirical data, we attempt to apply the theoretical framework of prestige and image LP to examine the status of Chinese in a Singaporean context. Through a correlative analysis of children's language use and the family's socio-economic status, we found that the Chinese language (CL) gradually lost its prestige in Singapore's society in general, and in particular it has lost ground to English in what Bourdieu terms as 'linguistic capital.' We argue that the future success of language policy in term of Chinese language maintenance, by and large, depends upon whether and how its prestige and image are being promoted. Our analysis therefore contributes to alternative vistas on the understanding of the official discourse towards language issues in a multicultural society.

Singapore has developed and implemented a policy of "English-knowing" bilingualism by which English, although not Asian in origin, has come to attract local communication networks, to grow as a legal language and a de facto national language used not only in government administration, law, business, workplaces, and between different ethnic communities, but also as medium of instruction in the school system. Meanwhile, Chinese, Malay and Tamil are defined in specific Singaporean terms as official mother tongues (MT) maintained and taught as school subjects with their proficiencies seen as enabling direct access to cultural traditions and related values of the Singaporean ethnic communities. Thus, the Singapore "Englishknowing" bilingual policy, in international bilingual terms, is pluralistic with a unique arrangement: English and Chinese, English and Malay, English and Tamil (Lo Bianco, 2007). Among them, the dominant pairing, however, is English and CL, not only because it involves two different orthographic systems but also more importantly it involves the 
majority of the Singaporean population (Chinese accounts for $76.8 \%$ of the total according to Population Census 2000) among other factors. Therefore, "the maintenance of a balance between English and CL has long been perceived as essential for building a unique language ecology needed for Singapore's social cohesion and indeed nation building" (Shepherd, 2005, p. 13).

This English-knowing bilingual policy has been perceived by many local and international scholars (e.g., Kaplan \& Baldauf, 2003; Goh, 2004; Xu \& $\mathrm{Li}, 2002)$ as a success. In other words, most of the studies on Singapore LP have documented successful governmental interventions and have taken the view that the government has effectively managed the school system and public media, and used public campaigns to maintain a high level of communicative integration between different ethnic and dialect groups. They believe that this communicative integration has contributed greatly to the socio-ethnic consolidation and incorporation of varieties of languages into a uniform system of communication that serves the national goals of development.

Recently however, some scholars have begun to address issues of the status planning and outcomes of the Singapore English-knowing bilingual policy from a critical point of view. For example, drawing from Bourdieu's theory of capitals and fields, Silver (2005, p. 61) argues that the policy discourse "has overlooked the permeable boundaries of fields: as the market develops, the value of capital can change as can perceptions of what constitutes capital." In other words, despite the government's intention to maintain symbolic and cultural capital in the MTs, with English acquisition as merely economic, the new values (e.g., symbolic) associated with English have become part of the local linguistic landscape, and inculcated into social, family, and individual habitus. Here Silver provides the underlying rationale for the outcome of the bilingual policy: a gradual but significant shift from a predominant use of Chinese to that of English within the Chinese community. Taking a historical-structural stand (Tollefson, 1991), Tan (2003, p. 48) observes that the country is very close to a situation where "linguistic differentiation is marked by social stratification," and he observes that the government is aware of the uneven power distribution between English speaking citizens and those who are less proficient in English and tries to obliterate the tension and to achieve the official agenda for minimal socio-political disturbances.

Despite the academic efforts of examining the LP issues from various perspectives, most of these studies are descriptive, with a focus on status planning which is mainly about the position of languages in society from the perspective of the government mandate. They fail to see one of the more essential factors in analyzing LP implementation, that is, the perception of the planned product by the recipients whose feeling and willingness ultimately will determine the final acceptance of the official policy. This is the very theme that has drawn a great deal of attention over the recent years, and this study attempts to apply it in examining Singapore LP as a case by using empirical data collected from the recipients of the bilingual policy. In accordance with the latest revised LP framework, particularly the issues concerning prestige and image components highlighted by Haarmann (1990) and Ager's (2005a; 2005b) work, we believe that language policy and implementation cannot be fully understood by merely looking into policy priorities and implementation designed from the top. We believe that investigating the relationship between the social economic background and children's language use at home is essential in discovering whether prestige and image as important parameters are established, and how they can be applied to account for a specific case like Singapore which is a multilingual and multicultural society.

In this study, we first highlight the theoretical perspective we have taken. Secondly, we describe data and research method. Then, we present the relevant empirical findings within Ager's framework about prestige and image planning and discuss the relationship between children's home language (HL) use and children's parents' socioeconomic background. We conclude this paper with some 
implications that underlie LP implementation in the future Singapore context.

\section{THEORETICAL PERSPECTIVE OF PRESTIGE/IMAGE COMPONENT IN LP}

LP has grown out of the practical need to solve the language problems arising from nation-state building in the aftermath of WWII. Early LP practitioners took a technicist view that language can be planned through state mandate policy with a special focus on language form modification (e.g., codification such as graphitization, grammatization and lexication) and on function cultivation (e.g., terminological modernization, stylistic development). This two-foci model, known as status versus corpus dichotomy of LP, has dominated general LP activities until very recent time. However, this model pays little attention to a more fundamental but hidden agenda - human behavior and psychological aspects in receiving the planned result.

The dominant model has been challenged in the LP research literature since the early 1990s when some LP scholars began to examine the LP implementation from a recipient perspective, leading to the view that more emphasis should be placed on the acceptance of the LP products, as well the recipients' attitudes towards them. Haarmann is considered to be the first scholar who has done a series of studies exploring the individual's role in the process of acceptance and rejection of LP provisions during 1980s to 1990s (Baldauf, 2005). In his 1990 theoretical framework, Haarmann insists that prestige planning be treated as a separate range of LP activities. In his view, corpus and status planning are productive activities, whereas prestige planning is a receptive or value function which influences how productive planning activities are acted upon by policy makers and received by the people. To build up the prestige of the planned products, Haarmann argues that LP should occur at four different levels (i.e., activities of individuals, group activities, activities of agencies and governmental activities), which represent differential prestige or efficiencies of organizational impact, and that planning as such, in turn, affect the success of the overall LP. In Haarmann's model, while he does not deny the impacting efficiency of a top-down approach (role of governmental and official agencies), a bottom-up approach (the individual and unofficial institutional role) for the first time was formally recognized and highlighted. Concurring with Haarmann, we would also like to emphasize the cooperative nature of LP actors, indicating that the success of planning activity (language policy) and its implementation (language planning) may depend on multiple impacts, and that many of these prestige planning activities involve cooperative behavior between individuals and across groups. As was noted by Baldauf (2004, p. 383) "when this cooperative language promotion behavior breaks down, it may be one factor that undermines policy development and planning practice, making it difficult to achieve the productive goals."

To theorize LP research as an independent academic area, Kaplan and Baldauf (1997) have further developed Haarmann's theoretical construct where, apart from prestige, language-ineducation planning, or acquisition planning in Cooper's (1989) term, is also integrated as an independent component of LP activities, paralleling the two traditional problem areas. In later development, Kaplan and Baldauf (2003, p. 202) further divide the prestige planning into three major components, namely, language intellectualization (including language of science), language of professions and language of higher culture. More recently, Ager (2005a; 2005b) further advances the receptive theory by distinguishing four theoretical concepts: status, prestige, identity and image. While pointing out that status and identity are "real or concrete aspects of language use," he is of strong opinion that prestige should be recapitulated from socio-psychological aspects. According to Ager (2005a, p. 1040) "[B] oth image and prestige need a basis of factual change in identity and status, but changes in status and identity do not necessarily bring about changes in image or prestige." In other words, image and prestige planning are as equally important if not more than status planning. 
However, image and prestige planning is different from status planning in terms of approach. Status planning is normally implemented through coercive approaches that are typical of top-down methods, whereas prestige/image planning requires a bottom-up oriented planning, typically by democratic and persuasive means. For instance, prestige planning points towards attitude change and identity formation through benign and less provocative measures; it emphasizes the effectiveness of participatory models and assigns great importance to collaborative support from the targeted population for which the language products are planned. Referring back to the aforementioned Harrmann's bottom-up (individuals and groups activities) level promotion, prestige planning is democratic and persuadable as it can only be shaped by long term cultivation. According to Bem's (1970, p. 79-88) Modeling Theory, people "are heavily influenced by the views of groups with which we identify, whose approval we want, or we regard as authority." If a planned product is used by prestigious public figures (individual promotion), as linguistic behavior represented by influential citizens and social elites serves as a reference point for the whole society, it provides the population with prestigious models to follow, resulting in spontaneous imitation and quick spread. Thereby, the most effective methodology is through a participatory model starting through bottom-up modus operandi of LP decision-making process.

Language is generally perceived by sociolinguists as the emblem of identity. The socioeconomic status of the possessors of a particular language denotes the prestige and image of the language itself, and thus effects people's perceptions of language choice as the language is seen to bestow socioeconomic marks on its speakers. To examine the actual prestige and image of CL in current Singapore society from the perspective of the latest development in the LP framework noted earlier, in what follows we will use the data of our research project as evidence to show how the prestige/image of CL is effected in the competition to English in terms of symbolic capitals in the Singapore linguistic market, thus providing implications for engaging the prestige planning in the state's future LP venture.

\section{DATA AND METHOD}

The data we used in this paper is obtained from a questionnaire survey entitled "An Investigation of Chinese Competence of Singaporean Preschoolers: A Corpus Study" (for details, see Zhao \& Liu, 2007). The main study is corpus driven where a computer corpus is established with the oral production of 600 Singaporean Mandarin speaking preschoolers.

Questionnaire survey is a part of the main project which aimed at obtaining the important referential information for subject sampling as well as the valuable background information to facilitate the data elicitation process. Before starting the fieldwork of data collection, approximately 1,200 questionnaires were administered to the parents of potential subjects. The information we intended to obtain from the questionnaire can be divided into three parts: part one focuses on information about the parents' socio-economic status; part two is the central concern of the survey, i.e., family language use, and part three is about their attitudes and hopes towards their child's welfare. 907 questionnaires were collected and processed for analysis. In the following discussion, only those parts of the data relevant to our current concerns are used.

One of the foci in this research project is to categorize children's language use at home. In the previous studies, Singaporean Chinese children are classified into two main groups: predominant English Speaking Family (ESF) and the predominant Chinese Speaking Family (CSF) groups. This distinction is typically made by one question item of the parent self-report of their language use at home at the students' primary school admission (CLCPRC, 2004, p. 4). We assume that the distinction made in this way is too simplistic to capture the complicated phenomenon of language use in Singapore households. This is mainly because according to our data, it is almost 
impossible for a child to live in a pure monolingual home in a multilingual society like Singapore. For instance, taking into account all forms of linguistic input, in only about $5 \%$ of families ( $4.2 \%$ for ESF and $0.8 \%$ for $\mathrm{CSF}$ ) is a child confined to pure monolingual exposure, i.e., listening, speaking, watching and reading only one language.

In order to have a better understanding of which language the preschoolers use predominantly at home, we take a holistic stance by using a multiple factor approach to define the preschoolers' HL use. The multiple factors include: a) parent's language use with their children (e.g., English or CL or both); b) parents' and children's TV/radio viewing or listening in terms of language channels; c) reading materials in English or CL or both, and d) children's language use with their peers and caregivers. These are important factors that can be considered to contribute to determining children's predominant language use at home and each factor has different contributing values. The parents' oral language use was assigned the biggest weight (50\%), following by the viewing and/or listening TV/radio programs in terms of English or Mandarin or both (30\%), reading materials in English or Mandarin or both (15\%), and finally the children's language use with their peers and caregivers $(5 \%)$. The four factors were computed against different percentage weighting of the quantifiable variables (four choices under each question item). The weighting percentage was determined by the coefficient correlation between the child's oral productivity (oral vocabulary) and various possible influential variables in survey questionnaire through the calculation of the coefficient of determination which is the square of the correlation coefficient, an index showing the degree to which one can predicate one variable from the other in percentage term (for details about differentiation steps and computation, see Liu \& Zhao, 2007; Zhao, Liu \& Hong, 2007).

By calculating the scores of these four factors, children's language use at home can be categorized into ESF, English-Chinese Speaking Family (ECSF) and CSF as shown in Table 1 with other demographic variables. It might be worthy to point out that ECSF is not necessarily a code-switching model in daily communication, but it might be necessary to take into account all relevant factors found in domestic linguistic life. The educational sector is another major concern of this study, so attempts were made to ensure that the sample size of each group is as proportional as possible to the actual ratio among the three major types of preschooling services in Singapore.

Table 1.

General Information on the Parents

\begin{tabular}{|lccc|}
\hline \multicolumn{2}{|l}{ Background Info $(\mathrm{n}=907)$} & Number & Percentage \\
\hline \multirow{2}{*}{ Age } & 5 & 459 & 50.6 \\
\hline \multirow{2}{*}{ Gender } & 6 & 448 & 49.4 \\
\hline \multirow{3}{*}{ Educational Sector } & Male & 460 & 50.7 \\
\cline { 2 - 4 } & Female & 447 & 49.3 \\
\cline { 2 - 4 } & Chublic Sector (19) & 459 & 49.9 \\
\cline { 2 - 4 } & Private Sector $(8)$ & 172 & 31.1 \\
\hline \multirow{3}{*}{ Home Language } & English & 264 & 19 \\
\cline { 2 - 4 } & Chinese & 211 & 29.1 \\
\cline { 2 - 4 } & English and Chinese & 432 & 23.3 \\
\hline
\end{tabular}




\section{FINDINGS: LANGUAGE USE} AND SOCIALSTRATIFICATION

In the following analysis, four socioeconomic indicators, namely, housing condition, occupation, educational qualification and type of kindergarten, were first tabulated to show how linguistic differentiation marks stratification by social class. And then, the status of English in the Chinese community was exemplified through the analysis of parental attitudes toward medium choice when conversing with their offspring.

\section{The correlation between socioeconomic background and language use}

This study did not investigate such sensitive topics as annual income or any other financial information because of ethical issues. Nevertheless, in Singapore, housing is sufficient criteria to determine a family's financial status as the HDB (Housing Development Board) exercises a policy of pegging income ceiling closely to property allocation. In this sense, it is valid for the housing facilities in this study to be read as the key parameter in assessing financial condition. Table 2 shows that there is a strong positive connection between the housing types and the household language uses. The families living in the most expensive private or commercial properties scored the highest percentage in using English (36.7\%), which is in a sharp contrast with $6.2 \%$ in the CSF group of the same type of housing. Next to this elite group are the five-room or executive flat owners, which, generally speaking, are also locally seen as fairly being middle class. Their score of $47.0 \%$ for ESF is also remarkably higher than CSF, which is $32.2 \%$. But the difference of $14.8 \%$ (47.0\%-32.2\%) between ESF and CSF of this category is notably lower than the more affluent families, which is $30.5 \%$ (36.7\%-6.2\%), almost two to one difference. This tends to indicate that the higher the socioeconomic ranking of a family, the more likely it is that English is spoken in the household.

At the lower end of socioeconomic assessments, in terms of relationship between the residential facilities and HL use, a similar trend is also readily observable. Chinese is more spoken among the lower end dwellers, whereas English is much less spoken in these families. $46.0 \%$ of four-

Table 2.

Housing type and home language used

\begin{tabular}{|clccc|}
\hline \multirow{2}{*}{ Reasons stated } & $\begin{array}{l}\text { Number and } \\
\text { percentage }\end{array}$ & ESF & CSF & ECSF \\
\cline { 2 - 5 } & N=264 & N=211 & N=432 \\
\hline Condo/Apartment / & Number & 97 & 13 & 80 \\
\cline { 2 - 5 } landed property & Percentage & $36.7 \%$ & $6.2 \%$ & $18.5 \%$ \\
\hline $\begin{array}{c}\text { 5-room HDB flat/ } \\
\text { executive flat }\end{array}$ & Number & 124 & 68 & 198 \\
\cline { 2 - 5 } & Percentage & $47.0 \%$ & $32.2 \%$ & $45.8 \%$ \\
\hline 4-room HDB flat & Number & 30 & 97 & 117 \\
\cline { 2 - 5 } & Percentage & $11.4 \%$ & $46.0 \%$ & $27.1 \%$ \\
\hline 3-room HDB flat & Number & 6 & 29 & 35 \\
\cline { 2 - 5 } & Percentage & $2.3 \%$ & $13.7 \%$ & $8.1 \%$ \\
\hline
\end{tabular}

Note: The percentages do not add up to $100 \%$ as there were cases where the subjects were allowed to choose 'others', and there are cases the value is missing, i.e., no filling. 
room flat residents are CSF, compared to $11.4 \%$ ESF within the same housing condition. For threeroom flat residents, there are even fewer ESF, the number of CSF (29) is not big either (in a purely numerical sense) as nowadays three-room flat residents are the minority of the total population. The fact that there are still more CSF than ESF in percentage, $13.7 \%$ and $2.3 \%$ respectively, is still noteworthy.

When it comes to ECSF, first of all, we can see that the larger number of families (432) is somewhere in the middle between Chinese predominant (211) and English predominant (264) modes. In other words, there is a wide stretched continuum in terms of linguistic ambience at home rather than a clear-cut binary dichotomy between ESF and CSF. Another important point revealed in the ECSF column is that the absolute majority of ECSF $(45.8 \%+27.1 \%=72.9 \%)$ are middle (four-room HDB flat) or upper- middle (five-room HDB flat or executive flat) class families. This seems to suggest that families at extreme socioeconomic ends are more likely to be monolingual (in relative terms), particularly for three-room HDB flat dwellers, whose frequency of code switching/ mixing is probably much restrained by the English proficiency of family members. This may explain the lower rate $(8.1 \%)$ as compared to the other three socioeconomic categories in subsequent discussion.

Putting all threads together, the above data analysis shows a neat parallel between the residential conditions and the languages used at home. In terms of the combined scoring of higher socioeconomic end (owners of commercial property and expensive five-room HDB flat and executive HDB flats), ESF account for $83.7 \%$ $(36.7 \%+47.0 \%)$, while for CSF the percentage is $38.4 \%(6.2 \%+32.2 \%)$, i.e., the ESF scored a double percentile of the CSF among the private property owners luxury HDB flat dwellers. Similarly, the reverse pattern was found in the combined scoring of lower socioeconomic status (four-room and three-room HDB flat). In this category of housing facilities, the rate of the CSF is significantly higher than that of the ESF with
$59.7 \%(46.0 \%+13.7 \%)$ and $13.7 \%(11.4 \%+2.3 \%)$ respectively. The close positive correlation between housing conditions and the HL inclination suggests an interesting phenomenon about the trope of residence; what type of house one lives not only becomes a barometer of social stratum, but more significantly, is also closely linked to what language one speaks, the lower income parents are more likely to talk to their offspring in Chinese, and vice versa.

A similar trend is observed when the other three major socioeconomic criteria were examined: there is a close fit between the family socioeconomic status and the predominant languages used at home as showed in Table 3. Due to space constraints, we tabulate all three socioeconomic indexes in the same table for easy comparison, and in what follows, leaving the trivial but evident variables, only those most significant ones are discussed.

First, we start with the educational attainment of the parents. As expected, the demarcation line between the education level and HL is neat and obvious. More than half (54.9\%) of ESF mothers obtained tertiary education, whereas for CSF mothers it is only $14.7 \%$. In contrast, the level of the mothers' education in the CSF group is nearly double of that in the ESF in the middle range of education level which is $62.6 \%$ vs. $38.6 \%$, and more so in the lowest level, in which there are 33 CSF mothers who only obtained primary school certificate, accounting for $15.6 \%$ of the group. The same number for ESF mothers is almost negligible $(1.9 \%)$. If we focus on the tertiary level column, the predictability of the relation between educational level and HL is most perfectly manifested by the descending order of scores from ESF, ECSF to CSF, $54.7 \%, 34.0 \%$ and $14.9 \%$ respectively. Among the fathers, the same pattern emerging among mothers also holds true to most cells in the father's section, with the exception of disparity in the tertiary and secondary levels of ESF (72.0\% vs. $22.3 \%$ ), which is remarkably wider than those of the mothers' section in the same categories of HL, which is $54.9 \%$ vs. $36.8 \%$. However, in the CSF category, the reverse is true, i.e., the difference between secondary and tertiary 


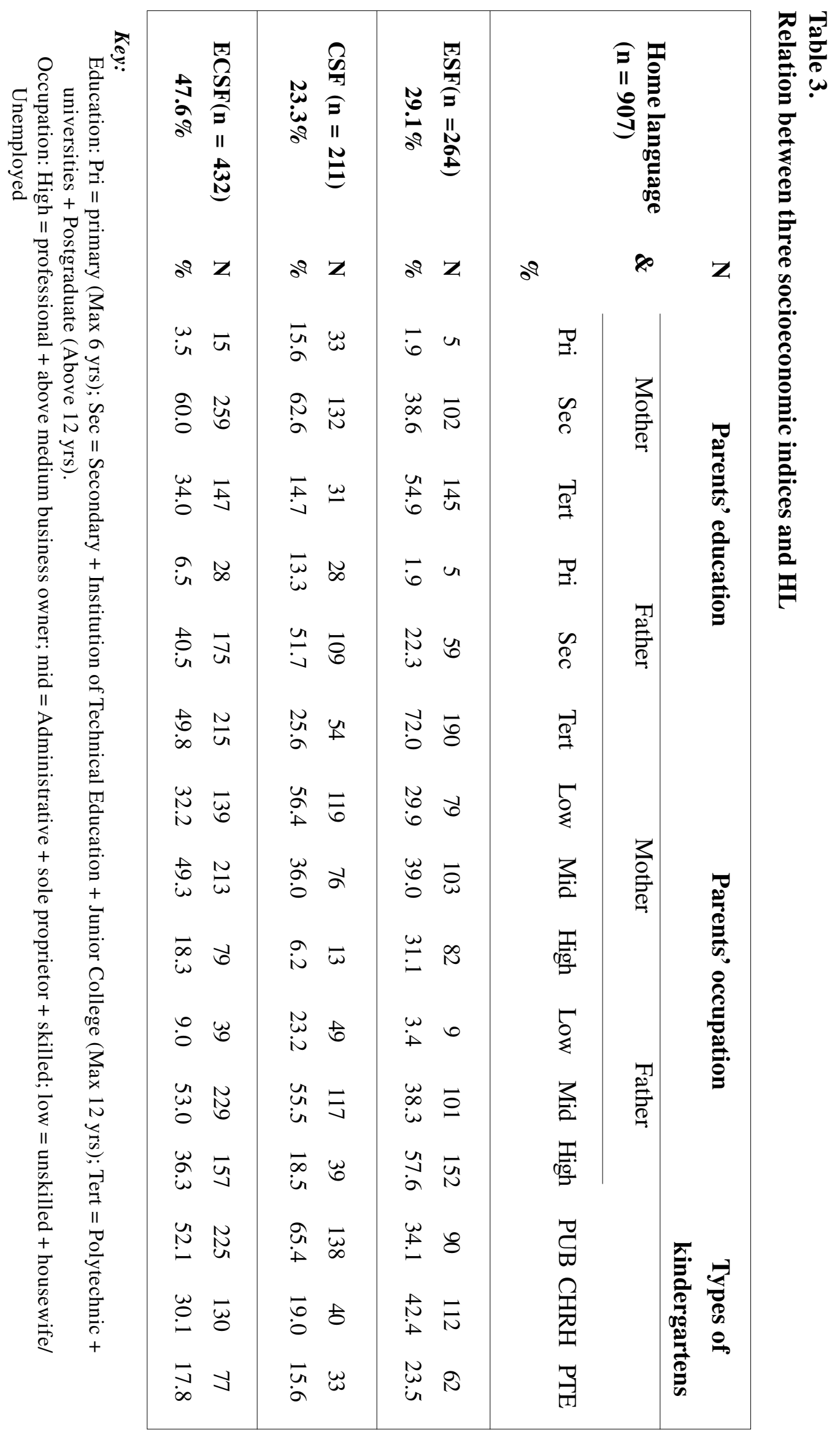


education level (62\% vs. $14.7 \%$ ) is significantly larger than those of the fathers' section, which is $51.7 \%$ vs. $25.6 \%$ respectively. It is interesting to note that the discrepancy appears to suggest that while the father's education plays a significant role in the greater use of English at home, language use within the CSF is probably governed to a greater extent by the mother's education rather than father's. In fact, if we turn to the next socioeconomic index, this phenomenon is also applicable to the parents' occupation. In other words, it also can be said that in the Singapore society, the mothers' educational and occupational differences have much greater influence than those of the fathers'.

Moving from education to the occupation factor, it can be noted that the correlation pattern between the HL and the three educational levels parents received is found to be roughly parallel with the relationship between HL and the three types of parents' occupation. That is, the higher range of occupation types is associated with more use of English at home and vice versa, the lower end of occupation types matches with the use of CL. Although no notable differences are found between mothers in the ESF and CSF group in terms of mid-range occupations $(39.0 \%$ vs. $36.0 \%$ ), the differences in the other two ends of the occupation types between two linguistic groups of family are remarkable. For instance, looking at occupations of ESF and CSF mothers, $31.1 \%$ of ESF mothers are professionals and entrepreneurs, while only $6.2 \%$ of CSF mothers is in the same category of occupation. In contrast, the percentage of unskilled working or unemployed mothers at CSF is $56.4 \%$, which is almost double of that of ESF (29.9\%). When attention is turned to the fathers' occupation, although what is revealed in the mothers' section is basically commensurate with the fathers' side generally, the disparity in the father's occupation between two kinds of family is more polarized. For example, in the range of high income occupations, the percentage of ESF fathers is thrice the number of CSF father, i.e., $57.6 \%$ against $18.5 \%$. In addition, the distance is more wildly disparate; approximately five times more fathers of CSF are working in unskilled sectors or are unemployed compared to their ESF counterparts. While this confirmed the findings reported in Xu, Chew \& Chen (2003) about the functional distribution of English and Chinese in various business sectors which is characteristic of a diglossia society, it also gives the impression that fathers who use English in the work place are more likely to use English rather than Chinese when interacting with their children in familial settings. Finally in this table, the type of kindergarten also serves as an index of social status, although it appears not to be as acutely sensitive as the other two factors. Preschool services in Singapore are run in a form of tripartite model according to the funding sources and governance: public, missionary and private. According to Khoo (1990) and Ko (1992), public childcare centers and kindergartens are governmentally institutionalized sectors mainly providing childcare and educational service to surrounding neighborhoods composed of working class families. The private and missionary ones have better trained teachers, centrally located and well-equipped, thus attracting children from the offcircle areas because of their prestige.

From Table 3, we can see that there are notable correlations between the aforementioned variables (education and occupation) and kindergarten type. Due to the elite nature of private kindergartens, the majority of children attending these preschools are children from affluent ESF (23.5\%), followed by relatively better off ECSF (17.8\%), while the CSF children (15.6\%) have the least opportunity to be educated in private kindergartens. Although the public funded kindergartens are not absolutely shunned by the middle and upper class families $(34.1 \%)$, the percentage of the higher socioeconomic families is comparatively smaller than that of the ECSF (52.1\%) and even smaller than that of the CSF (65.4\%). More specifically, if we combine the prestigious private and missionary ones, about $65.9 \%(42.45 \%+23.55 \%)$ of the parents in ESF and $47.9 \%(30.1 \%+17.8 \%)$ ECSF send their children to start their early 
formative years in these kindergartens, while only about $34.1 \%(19.0 \%+15.6 \%)$ disadvantaged CSF can afford to do so. This demonstrates that CSF children are also disadvantaged in their first language acquisition (i.e., English in official discourse) as it is an indisputable fact that the colloquial variety instead of standard Singapore English is more often used in public kindergartens. This finding can be further confirmed by the parental attitudes towards the language choice in their daily lives.

\section{The influences and implications of parents' language inclination}

Table 4 highlights the relationships between the parents' proficiency in spoken English and their choice of language in conversing with their child. The most significant tendency emerging from the data is that the parents collectively move toward interacting with their children in English rather than Chinese, even when they themselves are not confident in their own oral expression, this "step-mother tongue" (Gupta, 1994) in their own perception. While $65.9 \%$ mothers and $58.6 .0 \%$ fathers considered their spoken English as "good," there are only about $28.7 \%$ of mothers and $37.8 \%$ of fathers who chose 'very good' when asked to self-evaluate their English oral competence. This corroborates Tan's (2003, p. 56) earlier observation that "educated, highly socio-economically positioned English users constitute only a minority of the population." The language parents use in talking with their children is obviously the most important factor that determines the child's linguistic behavior, thus was given the top priority in our multiple factors method of HL classification. Therefore, if it is only the parents who chose 'very good' who are to be considered confident English speakers, then among most English speaking families, only about one-third of the parents are fully confident and comfortable in conversing with their child in English. For instance, 5.4\% $(0.3 \%+5.1 \%)$ of the mothers and $3.2 \%$
$(0.3 \%+2.9 \%)$ of the fathers who chose 'very poor' and 'not good' in oral English, but preferred to use English when talking to the child at home.

The data shows that there seems no correlation between the parents' English competence and their inclination to encourage their children to develop their oral ability of using Chinese. Previous studies (e.g., Kwan-Terry, 1991) tended to believe that in a bilingual community like Singapore, parents normally tend to immerse the child in the language that they are less exposed to so that they can be truly bilingual. As shown in the Table 4, there is no significant difference between theirEnglish proficiency and their inclination to use Chinese. Contrary to this, the better English-speaking parents are more likely to use English when talking to the child. Among mothers who move towards the use of Chinese with their children, the combined percentage of mothers in the CSF group who perceived themselves to be poor ('very poor' and 'not good') in speaking English is $61.2 \%(17.3 \%+43.9 \%)$ and the good Englishspeaking mothers is $38.8 \%(36.7 \%+2.1 \%)$. The percentage for fathers in both CSF and ESF groups are $50.2 \%(8.3 \%+41.9 \%)$ and $49.8 \%$ $(43.0 \%+6.8 \%)$ respectively.

As far as ECSF is concerned, parents speak both English and Chinese to child without clear dominance of any single language, as expected, the parents with medium level of oral English ('not good' and 'good') are more likely to speak both of the languages than those that put their oral English competence at the extreme end (i.e., either 'very poor' or 'very good' in speaking English). The total percentage of those parents who chose 'not good' and 'good' is $90.9 \%(14.6 \%+76.3 \%)$ for mothers and $85.1 \%(16.3 \%+68.8 \%)$ for fathers. On the other hand, while there are $60.9 \%$ $(17.3 \%+43.9 \%)$ of mothers who reported lower English level ('very poor' and 'not good') and who speak Chinese with their child, the rate for fathers in the same Chinese group is $50.2 \%$ $(41.9 \%+8.3 \%)$ The $10 \%$ difference between the mother and father indicates that the mothers with lower proficiency in oral English are more likely to be monolingual (in Chinese) than fathers (referring to proceeding discussion). 
Table 4.

Parents self-assessed level of spoken English and the language used with child

\begin{tabular}{|c|c|c|c|c|c|}
\hline \multirow{2}{*}{$\begin{array}{l}\text { Parents } \\
(\mathrm{n}=907)\end{array}$} & \multirow{2}{*}{\multicolumn{2}{|c|}{ Level of Spoken English }} & \multicolumn{3}{|c|}{ Language(s) used with child } \\
\hline & & & English & Chinese & Mixed \\
\hline \multirow{8}{*}{ Mother } & \multirow{2}{*}{ Very poor } & Number & 1 & 48 & 4 \\
\hline & & Percentage & 0.3 & 17.3 & 1.4 \\
\hline & \multirow{2}{*}{ Not good } & Number & 17 & 122 & 42 \\
\hline & & Percentage & 5.1 & 43.9 & 14.6 \\
\hline & \multirow{2}{*}{ Good } & Number & 218 & 102 & 219 \\
\hline & & Percentage & 65.9 & 36.7 & 76.3 \\
\hline & \multirow{2}{*}{ Very good } & Number & 95 & 6 & 22 \\
\hline & & Percentage & 28.7 & 2.1 & 7.7 \\
\hline \multirow{10}{*}{ Father } & & Total number & 334 & 283 & 288 \\
\hline & \multirow{2}{*}{ Very poor } & Number & 1 & 23 & 4 \\
\hline & & Percentage & 0.3 & 8.3 & 1.5 \\
\hline & \multirow{2}{*}{ Not good } & Number & 10 & 116 & 44 \\
\hline & & Percentage & 2.9 & 41.9 & 16.3 \\
\hline & \multirow{2}{*}{ Good } & Number & 204 & 119 & 185 \\
\hline & & Percentage & 58.6 & 43.0 & 68.8 \\
\hline & \multirow{3}{*}{ Very good } & Number & 132 & 19 & 35 \\
\hline & & Percentage & 37.8 & 6.8 & 13.0 \\
\hline & & Total number & 349 & 282 & 269 \\
\hline
\end{tabular}

\section{DISCUSSION}

The above correlation analysis of family language use, language attitudes and the socioeconomic status reveals complex sociolinguistic implications. Among several tendencies that emerge from the analysis, we assume that at least the following three points deserve special attention from the language planning perspectives.

First of all, the correlation between family language use and the housing conditions as a key socioeconomic indicator which confirms the belief that Singapore has been rapidly developing toward a linguatocracy society (Pendley, 1983, p. 50) where social stratification is linearly marked by the symbolic power translated via linguistic differentiation. As evidenced in our data, there exists a strong positive correlation between residential facilities and family language use. The high correlation of Chinese use with the four low ends of socioeconomic data shows that the CL has been associated with poverty and marginality. This stigma would in turn cause the use of CL in households to continue declining, and the polarization of pupils along social class lines in their later formal schooling will only be a matter of time, if no action in prestige planning of Chinese language is taken by the policy makers.

Second, the viewpoint that parents' have a deliberate intention to cultivate their child's bilingual ability, i.e., the parents of English-speaking family would try to talk Chinese with their children and 
vice versa, is not supported by the data presented here. As a matter of fact, it is only the use of English that is encouraged by the parents to better advantage their children, be it in the ESF or CSF group. This is by no means surprising given the pragmatic and prestigious value of the English language.

Third, relating to the first point, the majority of parents (about two thirds) who are not 'very good' English speakers claimed to interact with their children in English. This supports the argument (see Gupta, 1994, p. 123, among others) that the family is an important source of colloquial English in Singapore. The discrepancy between the actual level of parents' spoken English proficiency and their strong will to introduce English to their children for daily communication purposes reminds us that, as a result of a poor command of English, the overuse of local variety and its intrusion into formal schooling from family background may pose a potential obtrusive factor in child's acquisition of standard English later on, which is the worry of some scholars (e.g., Kwan-Terry, 1991, p. 16) as the Speak Good English Campaign is another important composite part of official language planning endeavor and has been since 2000 .

To extend these arguments to a broader spectrum, the government's support for CL has long been disputable and leads to criticism of covert/ overt policy. It remains somewhat enigmatic to argue that there is a well-set step by step strategy of systematic containment of CL use in order to gradually spread English as claimed by $\mathrm{Xu}$ and $\mathrm{Li}$ (2003, p. 142). Nevertheless, what can be ascertained is that while the distinction of linguistic capital in English and MTs has been repeatedly emphasized in the official discourse of language policy, the evidence now reveals that CL is being gradually forced out of the home - the last fortress and sanctuary of the threatened ethnic languages as warned by many language planning professionals (e.g., Tollefson, 2006, p. 51). The government is obligated to act to prevent Chinese and other MTs from further de-culturalization caused by uneven distribution of 'cultural capital' as a result of individual linguistic behavior. It can be predicated that, fearing being left behind in the competition of grapping cultural capital, more and more parents, which are termed as "invisible planner" by Pakir (1994) for their considerable role in language shift over the last a couple of decades, will continue to change their familial vernaculars only for the reason of climbing the English-wrought social ladder, as history has already seen $(\mathrm{Xu} \&$ Li, 2003, p. 146).

In the current context, the new dimensions emerging in LP situation have provided both challenges and opportunities in language ecology maintenance. The constant growth of English dominant families and rapid subtraction of CL use from the family and private settings show that, apart from meeting the previous requirement of the proficiency improvement of CL, the LP policy makers have to face an immediate challenge to arrest the rapid continuing fall in the number of CSFs. CL is one of the three MTs which are legitimated as official languages in addition to English in the Singapore English-knowing bilingual policy discourse. However, Singapore is after all an English speaking dominant Chinese society in the Malay world (Lo Bianco, 2007). Consequently, a clash tends to occur when the encroaching English as a global language and Chinese as a language of the majority community inevitably come to compete as they enter into each others' officially designated linguistic capital fields. Despite governmental efforts to articulate English acquisition as merely pragmatic, English has come to gain more capital values. The HL shift from Chinese to English highlighted in our data analysis shows that English has begun to have high values in terms of cultural, social and symbolic capitals on top of its legitimated economic value in official discourse.

Recent documented studies (e.g., Stephen, 2005; Tan, 2006) show that, in the past, CL planning aiming at elevating CL position has mainly played out in the educational arena. However, in effectiveness, language acquisition planning has yielded two contrary outcomes in shaping today's linguistic landscape in Singapore: 1) it has been successful in achieving the goal of getting individuals 
to shift to English-knowing bilinguals and promoting English as the language of wider communication; 2) insofar as CL promotion is concerned, schooling has not proved to be an effective tool in bolstering language maintenance in Chinese community. During the 1970s and 1990s up till today, facing the threat caused by the suspicion from the powerful force of Chinese educated majority, the government has been applying successive acquisition planning activities and committing expensive funding at policy level in its efforts to address the Chinese community's dissatisfaction regarding the gradual declining level of CL, such as those governmentally sanctioned high-profile milestone reviews of MT education in the release of the All-Party Report in 1956 through 1990s and the latest in 2004 summarized in Cheah (2004) and Silver (2006). However, as the findings of this research and other empirical evidence have shown, not only does the acquisition planning not prevent CL from further declining, but the intergenerational transmission has become problematic because of the increasing decline of parents' preference for Chinese as a family language.

Kaplan and Baldauf (2003, p. 23-24; p. 182) have arguably pointed out that the educational site is the wrong place and the educational institution the wrong actor in LP, so the implementation is bound to fail without higher-level participation to integrate language-in-education into a more comprehensive status planning. This is the major justification why they find the need to revise and extend the Haugen's $(1966 ; 1983)$ corpus vs. status two range matrix model to a four range framework by including language-in-education planning and prestige planning as two other separate functional ranges. The usefulness of adding language-in-education and prestige planning to the traditional language planning framework manifests in the emphasis of the integration nature of language planning activities. The trajectory of language-education-planning development (e.g., Cheah, 2004; Shepherd, 2005; Silver 2006) tells that, albeit vibrant intervention from the government, since there is no centralized national language agency, most measures targeting the $\mathrm{CL}$ positional enhancement are implemented in isolation without being treated as a part of a broader set of objectives. People's language behavior governed by an upward mobility motivation in a bilingual society, the acceptance of a language at education level and preschool, or even at home is most effectively promoted through realization of the end value of that language in society. Now there are some new interests in promoting Chinese from the economic perspective, but to avoid further divorce between language promotion in schools and its societal position in a broader perspective inevitably involves a prestige planning.

Despite the contribution of official LP discourse to the success of planning, by way of contrast, little has been done about prestige planning and its role in LP activities. Indeed, the Speak Mandarin Campaign (since 1979) is taken as an example of successful prestige/image planning, but it is just an instance of internal image planning (Ager, 2005b) with the intention of conferring prestige on the formally minority-speaking Mandarin and to enforce it as standard version, or lingua franca by attacking inferior varieties (dialects) within the Chinese community. Thus, it has little effect on the CL position relative to English - its arch rival in society. Prestige and image planning is always conducted directing against a high prestigious language or languages varieties; in Ager's (2005a, p. 1047) term, it has to have its "enemy." The obvious current enemy is English, the planning goal is how to accord $\mathrm{CL}$ with a more attractive value and positive image in comparison with English.

\section{CONCLUSION}

The encroachment of English into the Chinese domain in the language ecology justifies the desirability of seeking an alternative approach (prestige planning) to reconcile the tensions revealed in our findings between a politics of language concerned with ethnicity and a sociolinguistic reality revolving economic power. 
The prestige planning advocates hold that status planning and language-in-education planning is only half the battle of the whole job; language planning goals (spread, shift, maintenance, revival, etc.) would not have happened without prestige planning, be it covert or overt. In this study we have identified the different patterns of HL use and the major indices of socio-economic status. These findings show that CL users are not only steadily declining in number, but more significantly, the prestige has consequently fallen far behind English. In the past, education has been the principal arena in which status manipulation was conducted; in the future, as already described, to promote CL to a level above what have been achieved so far, there is a need for prestige planning through extension of CL use in wider communication, particularly in higher prestige domains. As the position of English use at home continues to swell, managing the prestige of CL is becoming an increasingly salient issue. Of course, prestige and image manipulation alone cannot do the task, as no single component (corpus, status, prestige/image or acquisition) is sufficient to strengthen a language position, but prestige planning does provide a social condition for status change to happen. Ager (2005a, p. 1042) argues that expecting an actual rise of status without serious commitments in raising its prestige would be non-starter.

The economic growth in China can be regarded as an opportunity for language planners to raise CL's prestige, thus increasing the number of CL speakers and extending the language into new areas. For instance, the wider use of CL in government departments and other public domains has been periodically demanded by CL promoters (e.g., Chew, 2004, p. 12-3; Goh, 2004, p. 106; Shepherd, 2005, p. 134). The economic value of CL provides the basis and persuasive power for working on influencing public feelings and attitude, which are the purported targets of any prestige planning. Although CL has gained some economic value elsewhere through the status that accrues to the economic success of China, or the Chinese world as whole, the Singapore government has begun cautiously to build up contexts in its policy discourse in which CL has become useful in financial and business areas. The prestige of CL as a motivating factor in crafting the policy discourse has yet to be formally formulated due to the sensitive nature of the issue. Prestige planning is often a policy-oriented component involving how to position a certain language in relation to other languages within the language ecology of a society. The extension of CL to the new domains, as a means of promoting the prestige of CL, is bound to have governmental involvement.

The government should recognize that its officially constructed language ecology articulated in economic utility of English and cultural value of mother tongues is threatened by the emerging linguistic dynamics characterized by the permeability of language development. In our opinion, the government should seize the opportunity endowed by CL's new value in commercial areas to strike a new balance between English and CL in the linguistic capital field, and to increase the prestige of Chinese in the country. However, motivation for CL policy in Singapore arose from the overriding goal of maintaining the interethnic harmony, to promote CL prestige and to raise the status of CL, the leadership faces the challenge of how to ensure not losing the new balance between CL and other two MTs.

\section{AUTHOR NOTE}

The authors wish to express their gratitude to the research team members of the Project mentioned in the text, especially to Ms. Wendy Toh for her valuable technical support. We would also like to thank anonymous reviewers and editors for their comments and corrections on earlier versions of this article.

\section{REFERENCES}

Ager D. E. (2005a). Prestige and image planning. In E. Hinkel (Ed.) Handbook of research in second language teaching and learning (pp. 
1035-1054). London, U.K.: Lawrence Erlbaum Associates Publishers.

Ager D. E. (2005b). Image and prestige planning. Current Issues in Language Planning, 6(1), $1-43$.

Baldauf, R. B. Jr. (2004). Issues of prestige and image in language-in-education planning in Australia. Current Issues in Language Planning, 5(4), 376-388.

Baldauf, R. B. Jr. (2005). Language planning and policy research: An overview. In E. Hinkel(Ed.) Handbook of research in second language teaching and learning (pp 957-970). London, U.K.: Lawrence Erlbaum Associates Publishers.

Bem, D. J. (1970). Beliefs, attitudes, and human affairs. Belmont, CA: Brooks/Cole.

Cheah, C. M. (2004). The development of bilingual education in Singapore and the proposed areas of research on the teaching and learning of MT languages (CRPP Technical Paper). National Institute of Education at Nanyang Technological University.

Chew, C. H. (2004). Yuyan yи Yuyan Jiaoxue Lunwenji [Papers on language and language education]. Singapore: SNP Fan Taipingyang Chubanshe.

CLCPRC (Chinese Language Curriculum and Pedagogy Review Committee) (2004). Report of the Chinese Language Curriculum and Pedagogy Review Committee. Singapore: Ministry of Education.

Cooper, R. L. (1989). Language planning and social change. Cambridge, U.K.: Cambridge University Press.

Goh, N. W. (2004). Huayuwen Zai Xinjiapo De Xianzhuang Yu Qianjing [The Current Practice and Prospect of Chinese Language Education in Singapore]. Singapore: Chuangyiquan Chubanshe.

Gupta, A. F. (1994). The step-tongue: Children's English in Singapore. Clevedon, U.K.: Multilingual Matters.

Haarmann, H. (1990). Language planning in the light of a general theory of language: A methodological framework. International
Journal of Sociology and Language, 86, 103-126.

Haugen, E. (1966). Dialect, language, nation. American Anthropologist 68, 922-935.

Haugen, E. (1983). The implementation of corpus planning: Theory and practice. In J. Cobarrubias \& J. A. Fishman (Eds.), Progress in language planning (pp. 269-290). Berlin, Germany: Mouton de Gruyter.

Kaplan, R. B. \& Baldauf, R. B. Jr. (1997). Language planning: From practice to theory. Clevedon, U.K.: Multilingual Matters.

Kaplan, R. B. \& Baldauf, R. B. Jr. (2003). Language and language-in-education planning in the Pacific Basin. Dordrecht, Netherlands: Kluwer Academic Publishers.

Ko, P. S. (1992). The cognitive and social development of pre-school children in Singapore: What have we learned from the IEBvLF study? In P.S. Ko \& W. K. Ho (Eds.), Growing up in Singapore: The preschool years (pp. 135-68). Singapore: Longman Singapore Publishers (Pte) Limited.

Khoo, K. (1990). An alternative model of childcare: The experience of the National Trades Union Congress of Singapore. In B. P. Chan (Ed.), Early childhood toward the $21^{\text {st }}$ century (pp. 205-16). Hong Kong Yew Chung Education Publishing Company.

Kwan-Terry, A. (1991). Home language and school language: A study of children's language use in Singapore. In A. Kwan-Terry (Ed.), Child language development in Singapore and Malaysia (pp. 12-34). Singapore University Press.

Liu, Y. B. \& Zhao, S. H. (2007). An investigation of Chinese Singaporean children's oral competence in Mandarin: To construct an oral corpus and to generate a word list. Singapore: Ministry of Education.

Lo Bianco, J. (2007). Advantage and identity: Neat discourse but troubled union: Singapore's medium of instruction policy. In V. Vaish, S. Gopinathan \& Y. B. Liu (Eds.),

Language, capital, culture: Critical studies of language in education in Singapore (pp.524). Amsterdam: SensePublishers. 
Pendley, C. (1983). Language policy and social transformation in contemporary Singapore. Southeast Asia Journal of Social Science, 11(2), 46-58.

Pakir, A. (1994). Education and invisible language planning: The case of English in Singapore. In T. Kandiah (Ed.), English and language planning: Southeast Asia contribution (pp. 158-181). Centre for Advanced Studies, National University of Singapore.

Shepherd, J. (2005). Striking a balance: The management of languages in Singapore. Frankfurt am Main, Germany: Peter Lang.

Silver, R. E. (2005). The discourse of linguistic capital: Language and economic policy planning in Singapore. Language Policy, 4(1), 47-66.

Tan, C. (2006). Change and continuity: Chinese language policy in Singapore. Language Policy, 5(1), 41-62.

Tan, S. H. (2003). Theoretical ideals and ideologized reality in language planning. In S. Gopinathan, A. Pakir, W. K. Ho \& V. Saravanan. (Eds.), Language, society and education in Singapore: Issues and trends (pp. 45-64). Singapore: Marshall Cavendish International.

Tollefson, J. W. (1991). Planning language, planning inequality: Language policy in the community. London: Longman.
Tollefson, J. W. (2006). Critical theory in language policy. In T. Ricento (Ed.), An introduction to language policy (pp. 42-59). Malden, MA: Blackwell Publishing.

$\mathrm{Xu}$, D. M., \& Li W. (2002). Managing multilingualism in Singapore. In W. Li, J-M Dewaele \& A. Housen (Eds.), Opportunities and challenges of bilingualism (pp. 275-296). Berlin, Germany Mouton de Gruyter.

Xu, D. M., \& Li, W. (2003). Linguistic dirigisme and language management in Singapore. In P. M. Ryan \& R. Terborg (Eds.), Language: Issues of inequality (pp. 121-154). Universidad Nacional Autonoma de Mexico.

Xu, D. M., Chew, C. H., \& Chen, S. C. (2003). Language use and language attitudes in Singapore's Chinese community. In S. Gopinathan, A. Pakir, W. K. Ho \& V. Saravanan. (Eds.) Language, society and education in Singapore: Issues and trends (pp.133-154), Singapore: Marshall Cavendish International.

Zhao, S. H., \& Liu, Y. B. (2007). The generation of Mandarin oral corpus of Singaporean preschoolers [Xinjiapo huazu ertong kouyu yuliaoku de shengcheng]. Journal of Teaching Chinese in the World, 80(2) 98-105.

Zhao, S. H., Liu, Y. B., \& Hong, H. Q. (2007). Singaporean preschoolers' oral competence in Mandarin, Language Policy, 6(1), 73-94. 